\title{
Prediction of Tetraoxygen Reaction Mechanism with Sulfur Atom on the Singlet Potential Energy Surface
}

\author{
Ashraf Khademzadeh, Morteza Vahedpour, and Fereshte Karami \\ Chemistry Department, University of Zanjan, Zanjan 45371-38791, Iran \\ Correspondence should be addressed to Morteza Vahedpour; vahed@znu.ac.ir
}

Received 17 August 2013; Accepted 11 October 2013; Published 23 January 2014

Academic Editors: D. Dondi and B. Fernandez

Copyright ( 2014 Ashraf Khademzadeh et al. This is an open access article distributed under the Creative Commons Attribution License, which permits unrestricted use, distribution, and reproduction in any medium, provided the original work is properly cited.

\begin{abstract}
The mechanism of $\mathrm{S}_{+} \mathrm{O}_{4}\left(\mathrm{D}_{2 \mathrm{~h}}\right)$ reaction has been investigated at the B3LYP/6-311+G(3df) and CCSD levels on the singlet potential energy surface. One stable complex has been found for the $\mathrm{S}+\mathrm{O}_{4}\left(\mathrm{D}_{2 \mathrm{~h}}\right)$ reaction, IN1, on the singlet potential energy surface. For the title reaction, we obtained four kinds of products at the B3LYP level, which have enough thermodynamic stability. The results reveal that the product P3 is spontaneous and exothermic with -188.042 and $-179.147 \mathrm{kcal} / \mathrm{mol}$ in Gibbs free energy and enthalpy of reaction, respectively. Because $\mathrm{P} 1$ adduct is produced after passing two low energy level transition states, kinetically, it is the most favorable adduct in the ${ }^{1} \mathrm{~S}+{ }^{1} \mathrm{O}_{4}\left(\mathrm{D}_{2 \mathrm{~h}}\right)$ atmospheric reactions.
\end{abstract}

\section{Introduction}

The oxygen atom exists naturally in four basic forms including free atomic particle, diatomic oxygen $\mathrm{O}_{2}$, ozone $\mathrm{O}_{3}$, and tetraoxygen $\mathrm{O}_{4}$. Tetraoxygen is typically an unstable, rare, nonmagnetic pale blue gas. Interest in tetraoxygen molecules dates to a 1924 by Lewis [1]; since then, studies of $\mathrm{O}_{4}$ known as "oxozone" have enjoyed a long history of investigation [2-10].

Since its discovery, $\mathrm{O}_{4}$ has been a subject of interest from both experimental and theoretical point of views. The first experimental study of molecular oxygen by using spectroscopic method came back to Arnold and coworker's research [11]. They suggested the existence of $\mathrm{O}_{4}$ molecule as van der Waals complex. In addition, Helm and Walter [12], are observed formation of $\mathrm{O}_{4}$ molecules when electron transferred to form of $\mathrm{O}_{4}{ }^{+}$. The kinetic energy release and the nature of dissociation have been investigated using electronic excited state. The metastable structure of $\mathrm{O}_{4}$ molecule has been recently observed in mass spectroscopy experiments by Cacace et al. [13]. Then, Bevsek et al. [14] described 1:1 (or 1+1) resonant photoionization spectra of an energetic metastable $\mathrm{O}_{4}$ species produced in a dc discharge. In another study, Adamantides et al. defined a long-predicted covalent forms, either cyclic, $D_{2 \mathrm{~d}}$, or pinwheel, $\mathrm{D}_{3 \mathrm{~h}}$, structures [15].
In theoretical approach, Adamantides et al. (1980) [15] predicted the existence of metastable covalent $\mathrm{O}_{4}$ molecule completely different from the van der Waals structure of $\mathrm{O}_{2}-\mathrm{O}_{2}$ molecule which was experimentally detected. Then, Røeggn and Nilssen (1989) [16] have shown a branch form of $\mathrm{O}_{4}$ analogues with the stable isoelectronic molecules $\mathrm{NO}_{3}{ }^{-}$ and $\mathrm{OO}_{3}$. A central atom and three equivalent ligand atoms characterized it, which can exist in metastable $D_{3 \mathrm{~h}}$ form. In 1990, Dunn et al. [6] predicted a cyclostructure for $\mathrm{O}_{4}$ molecule with the bond length of $1.437 \AA$. In addition, dissociation of cyclostructure $\mathrm{O}_{4}$ molecule is investigated by Seidl and Schaefer [9] based on new high-energy materials. An ab initio calculation has been done on the ground and low-lying electronic states of $\mathrm{O}_{4}$ along the minimum energy to explain the reactivity and electronic state of tetraoxygen. Obtained results provided a solid basis to establish the stability of the $\mathrm{O}_{4}$ chemically bound molecule. In addition, surface crossings between singlet and triplet states were found and further characterized by evaluating their spin-orbit coupling matrix elements [7]. Peterka [5] present rotationally resolved photoionization spectra, photoelectron spectra, and ab initio calculations for providing strong evidence for the identity of this species as a novel complex between a ground state molecule and one excited state. In summary, theoretical 
calculations have predicted the existence of metastable $\mathrm{O}_{4}$ molecules with two different shapes: cyclobutane and trigonal planar similar to boron trifluoride. The existence of $\mathrm{O}_{4}$ was further confirmed in some other theoretical and experimental research $[14,17-20]$.

On the other hand, processes such as volcanic eruptions, biogenic activity, and fossil fuel combustion all contribute to the emission of sulfur gases into the atmosphere. Sulfur has long been recognized as an important constituent of atmospheric aerosols and sulfur compounds are major pollutants of the environment [21]. The sixteen molecular species of type $\mathrm{S}_{n} \mathrm{O}_{m}\left(\mathrm{SO}, \mathrm{SO}_{2}, \mathrm{SO}_{3}, \mathrm{SO}_{4}\right.$, etc.) have been detected experimentally [22]. Among these species, the sulfur dioxide $\left(\mathrm{SO}_{2}\right)$ molecule plays an important role in the atmospheric formation of sulfuric acid.

Sulfur tetraoxide $\left(\mathrm{SO}_{4}\right)$ as an interesting atmospheric compound is potentially relevant to atmospheric chemistry [23]. McKee [24] considered several structures for the $\mathrm{SO}_{4}$ species and predicted that the lowest-energy structure is to have a three-membered SOO ring and $\mathrm{C}_{2 \mathrm{v}}$ symmetry. Schriver et al. [25] also reported IR bands at 1,442 and $1,272 \mathrm{~cm}^{-1}$, which they attribute to $\mathrm{SO}_{4}$. Kugel and Taube [26] give a discussion of the synthesis and characterization of the monomeric $\mathrm{SO}_{4}$. Previously, sulfur tetraoxide has been proposed as intermediate in a variety of sulfur oxide reaction systems, as the active oxidizing species in persulfate oxidations [27]. Therefore, the experimental and theoretical studies reveal that the most stable structure for $\mathrm{SO}_{4}$ is a three-membered ring (SOO) with two terminal oxygen atoms attached to ring sulfur with $\mathrm{C}_{2 \mathrm{v}}$ symmetry $\left(\mathrm{SO}_{4}\left(\mathrm{C}_{2 \mathrm{v}}\right)\right) . \mathrm{SO}_{4}\left(\mathrm{C}_{2 \mathrm{v}}\right)$ molecule has been confirmed in both the experimental and theoretical studies, while $\mathrm{SO}_{4}\left(\mathrm{C}_{3 \mathrm{v}}\right)$ molecule has been only confirmed in the theoretical studies.

To our knowledge, there is not any theoretical or experimental work on the reaction mechanism of $\mathrm{S}+\mathrm{O}_{4}$ reaction. Hence, in this work the reaction mechanism of sulfur atom reaction with $\mathrm{O}_{4}$ molecule on the singlet potential energy surface are investigated. Then, thermodynamic parameters of the reaction are obtained and results the reaction is spontaneous with the releasing of the energy. As well as, the structure of $\mathrm{O}_{4}$ molecule and possible products are reported on the singlet potential energy surface.

\section{Computational Details}

All the calculations are performed with the Gaussian 03 system of codes [28]. The geometries of all species involved in the ${ }^{1} \mathrm{~S}^{1}{ }^{1} \mathrm{O}_{4}$ reaction are fully optimized at the B3LYP [29] level in conjunction with the 6-311+G (3df) basis set. The 6$311+\mathrm{G}(3 \mathrm{df})$ basis set has been used because of the lack of hydrogen atoms in structures. These energies are corrected by zero point energies of B3LYP level. In present study the coupled cluster singles and doubles (CCSD) method has been employed [30,31]. This method has the advantage of being able to evaluate the correlation surface in a size consistent manner. Hence, the CCSD calculations are carried out to compute accurate relative energies. The counterpoise procedure has been used to correct the interaction energy for basis set superposition error, BSSE, for the structures. So, the obtained energies are corrected by BSSE energies.

At the motioned level of treatment, we computed the vibrational frequencies to determine the nature of the stationary points according to the number of the eigenvalues of the Hessian matrix. The results show that one of reactants $\left(\mathrm{O}_{4}\right)$, products, and intermediates possesses all real frequencies, and any transition state has only one imaginary frequency. The imaginary frequency that characterizes each transition state is included as well. Another reactant, S, has no vibrational frequencies. To verify that the TS structure is the right saddle point connecting the corresponding reactants and products of interest, the intrinsic reaction coordinate, IRC [32], calculations were performed at the B3LYP level. These calculations show that all TS structures of title reactions are valid. At the level of this method, it is possible to generate a wave function in a suitable form to execute a topological analysis of atoms in molecules [33] using the AIM2000 series programs [34]. Moreover, thermodynamic data have been calculated using the statistical mechanics.

\section{Results and Discussion}

The reaction mechanisms of $\mathrm{S}$ with $\mathrm{O}_{4}$ have been investigated on singlet PES. One stable complex has been found between the reactants. Hence, all of the elementary reactions considered in the title reaction begin with the stable initial complex after passing corresponding transition states to produce final adducts. The intermediates prefix is IN followed by a number to differentiate one from each other. The transition states are designated by the prefix TS and a number. The structures of the reactants, products, intermediates, and transition states involved in the ${ }^{1} \mathrm{~S}+{ }^{1} \mathrm{O}_{4}$ reaction are shown in Figure 1. Their Cartesian coordinates are available in the Supplementary Material, available online at http://dx.doi.org/10.1155/2014/912391. By means of the TSs and their connected intermediates (or products), a schematic PES for the reaction is plotted in Figure 2. Table 1 gives the total energies for the B3LYP and CCSD levels and corresponding relative energies in comparison with the reactants in the singlet state. To simplify our discussion, the energy of reactant $\mathrm{R},{ }^{1} \mathrm{~S}_{+}{ }^{1} \mathrm{O}_{4}$, is set to be zero for reference. The AIM theory topological parameters for $\mathrm{O}_{4}$ as a reactant on the B3LYP level are exhibited in Figure 3. In addition, the topological characteristics in the bond critical points in the mentioned molecules are tabulated in Table 2. The vibrational frequencies of all species are summarized in Table 3. In addition, the values of the AIM theory topological parameters for selected bonds of products on the B3LYP level are shown in Figure 3. Then, the topological characteristics in the bond critical points, BCPs, in the molecules are tabulated in Table 4. The highest occupied molecular orbital, HOMO, and the lowest unoccupied molecular orbital, LUMO, energies and band gap energy for HOMO to LUMO transition of the selected species for products are shown in Table 5. In addition, frontier molecular orbitals of the same molecules are shown in Figure 4. Finally, the standard thermodynamic 


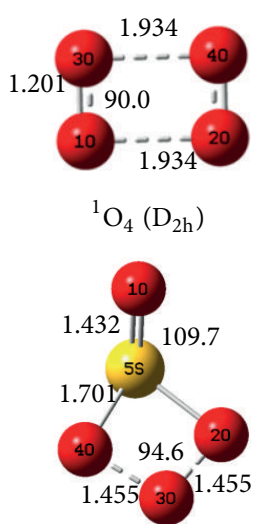

IN3

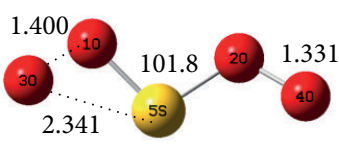

TS2

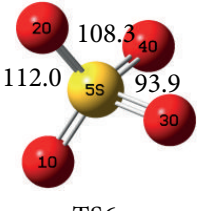

TS6
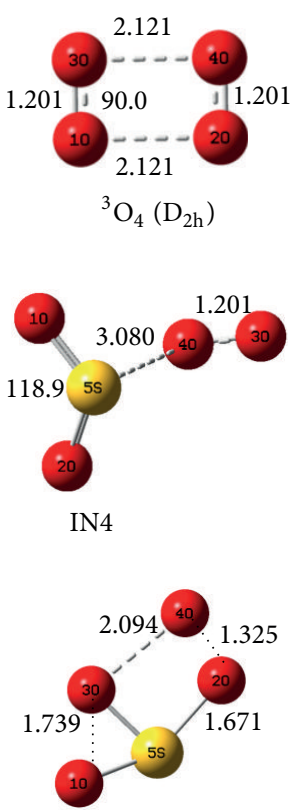

TS3

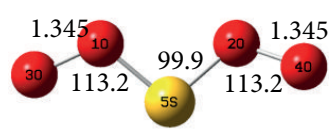

OOSOO

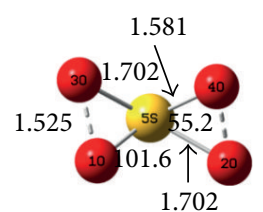

IN1
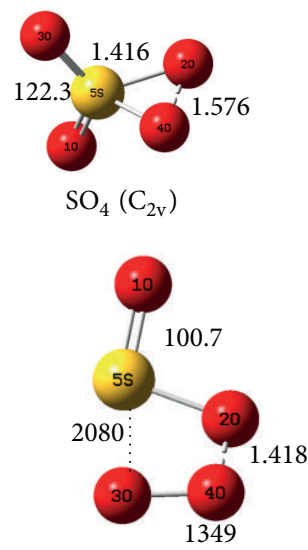

TS4

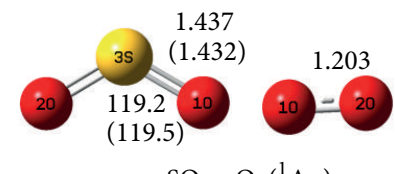

$\mathrm{SO}_{2}+\mathrm{O}_{2}\left({ }^{1} \Delta_{\mathrm{g}}\right)$

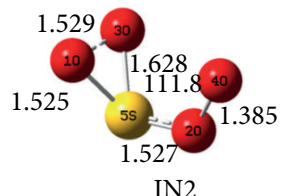

IN2

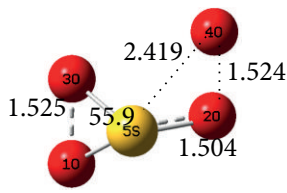

TS1

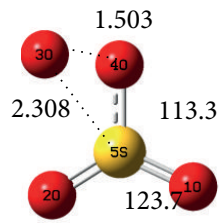

TS5

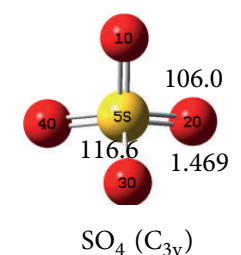

FIGURE 1: Geometries of reactants, products, intermediates, and transition states optimized on the singlet PES at the B3LYP level (bond distances are in angstrom and angles are in degree). The values in parentheses refer to experimental data [35].

functions at room temperature and atmospheric pressure are tabulated in Table 6.

3.1. $\mathrm{O}_{4}$ Molecular Property. Up to date, the experimental and theoretical studies show that $\mathrm{O}_{4}$ has different structures with various group points. In addition, its bond strengths and characteristic (van der Waals or covalent bonds) are discussed $[7,12,16]$. In our study, we applied the new structure of neutral tetraoxygen with group point of $\mathrm{D}_{2 \mathrm{~h}}$. Of course, in study of Helm and Walter, $\mathrm{D}_{2 \mathrm{~h}}$ group point of $\mathrm{O}_{4}$ with positive charge has been investigated. $\mathrm{O}_{4}\left(\mathrm{D}_{2 \mathrm{~d}}\right)$ has stability energy of -299.0706 au while its structure with the $\mathrm{D}_{3 \mathrm{~h}}$ group point shows stability energy of -300.0949 au. In addition, in the mentioned study of Helm and Walter, the bond length of $\mathrm{O}-$ $\mathrm{O}$ in the $\mathrm{O}_{4}\left(\mathrm{D}_{2 \mathrm{~d}}\right)$ is reported $1.433 \AA$ and angle of $\mathrm{O} 1 \mathrm{O} 2 \mathrm{O} 3$ atoms is $87.0^{\circ}$ while in the $\mathrm{O}_{4}$ with $\mathrm{D}_{3 \mathrm{~h}}$ point group, the $\mathrm{O}-\mathrm{O}$ bond length is obtained $1.330 \AA$ and angle of three mentioned atoms is $120.0^{\circ}$. In $\mathrm{O}_{4}{ }^{+}\left(\mathrm{D}_{2 \mathrm{~h}}\right)$, the bond lengths are 1.160 and $2.396 \AA$, which shows rectangular shape of molecule [12].

In the $\mathrm{O}_{4}\left(\mathrm{D}_{2 \mathrm{~h}}\right)$ on the singlet PES, our results confirmed that the bond lengths are 1.934 and $1.201 \AA$ with rectangular structure of molecule. The stability energy of that is $-300.6897 \mathrm{au}$, which is stable than the other structures with diverse group points on the singlet PES.
TABLE 1: The total energies (in Hartree) and relative energies (in parentheses and $\mathrm{kcal} / \mathrm{mol}$ ) of the reactants, products, and intermediates in the ${ }^{1} \mathrm{~S}^{1}{ }^{1} \mathrm{O}_{4}$ reaction on the singlet PES.

\begin{tabular}{lcc}
\hline Species & B3LYP & CCSD \\
\hline${ }^{1} \mathrm{O}_{4}$ & -300.6780 & -300.1169 \\
${ }^{1} \mathrm{~S}^{1} \mathrm{O}_{4}$ & $-698.7512(0.000)$ & $-697.7038(0.000)$ \\
${ }^{3} \mathrm{~S}^{1} \mathrm{O}_{4}$ & $-698.8125(-38.466)$ & $-697.7576(-33.760)$ \\
$\mathrm{IN} 1$ & $-698.9258(-109.524)$ & $-697.8998(-122.962)$ \\
$\mathrm{IN} 2$ & $-698.8887(-86.279)$ & $-697.8493(-91.305)$ \\
$\mathrm{IN} 3$ & $-698.9700(-137.288)$ & $-697.9428(-149.967)$ \\
$\mathrm{IN} 4$ & $-699.0211(-169.363)$ & $-698.0045(-188.706)$ \\
$\mathrm{TS} 1$ & $-698.8693(-74.095)$ & $-697.8344(-81.980)$ \\
$\mathrm{TS} 2$ & $-698.8327(-51.124)$ & $-697.7908(-54.616)$ \\
$\mathrm{TS} 3$ & $-698.8711(-75.231)$ & $-697.8172(-71.159)$ \\
$\mathrm{TS}$ & $-698.9510(-125.396)$ & $-697.9046(-125.983)$ \\
$\mathrm{TS}$ & $-698.9676(-135.760)$ & $-697.9385(-147.258)$ \\
$\mathrm{TS}$ & $-699.0077(-160.916)$ & $-697.9687(-166.210)$ \\
$\mathrm{OOSOO}$ & $-698.8598(-68.119)$ & $-697.7884(-53.090)$ \\
$\mathrm{SO}_{2}+\mathrm{O}_{2}\left({ }^{1} \Delta_{\mathrm{g}}\right)$ & $-699.0234(-170.792)$ & $-698.0023(-187.280)$ \\
$\mathrm{SO}_{4}\left(\mathrm{C}_{2 \mathrm{v}}\right)$ & $-699.0489(-186.769)$ & $-698.0316(-205.672)$ \\
$\mathrm{SO}_{4}\left(\mathrm{C}_{3 \mathrm{v}}\right)$ & $-699.0127(-164.089)$ & $-697.9665(-164.835)$ \\
\hline
\end{tabular}


TABLE 2: Topological analyses of $\mathrm{O}_{4}$ molecules on the B3LYP level; values are in atomic units.

\begin{tabular}{lcccccccc}
\hline Species & Bond critical point & $\rho(r)$ & $\lambda_{1}$ & $\lambda_{2}$ & $\lambda_{3}$ & $\nabla^{2} \rho(r)$ & Nature of bond \\
\hline${ }^{1} \mathrm{O}_{4}$ & Point 1 & 0.0817 & -0.1465 & -0.1199 & 0.6143 & 0.3479 & van der Waals \\
& Point 2 & 0.5523 & -1.4969 & -1.4626 & 2.2397 & -0.7198 & Covalent \\
\hline${ }^{3} \mathrm{O}_{4}$ & Point 1 & 0.0527 & -0.0813 & -0.0736 & 0.3691 & 0.2142 & van der Waals \\
& Point 2 & 0.5507 & -1.4961 & -1.4713 & 2.2321 & -0.7601 & Covalent \\
\hline
\end{tabular}

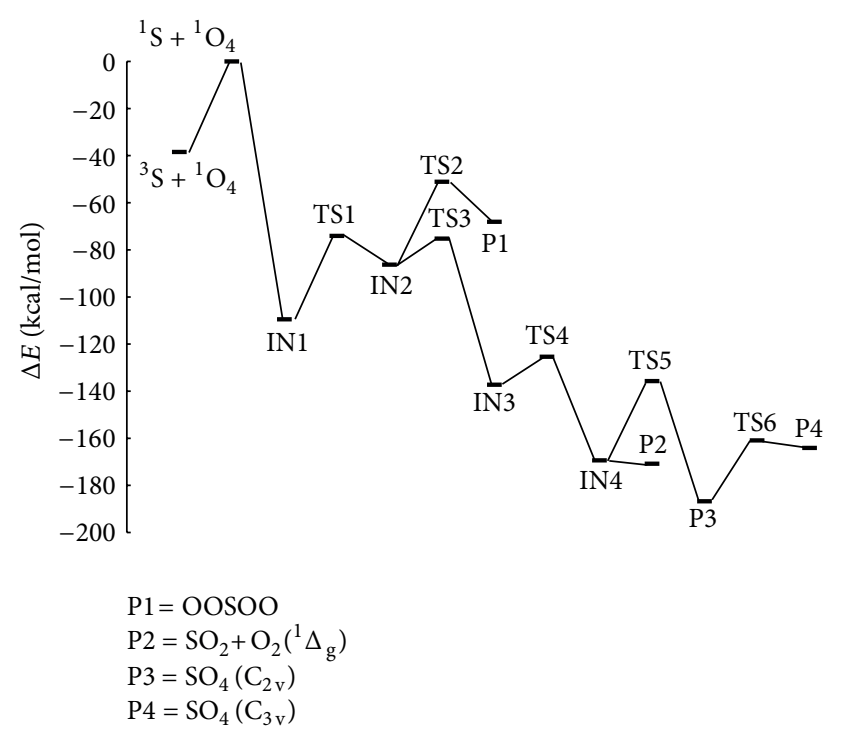

Figure 2: Profile of calculated potential energy surface of ${ }^{1} \mathrm{~S}+{ }^{1} \mathrm{O}_{4}$ reaction at B3LYP level of computation.

The bond formation between the oxygen atoms in the tetraoxygen molecule on the singlet and triplet states is confirmed by atoms in molecules topological analysis of wave function. This analysis reveals the presence of bond critical points located between $\mathrm{O}_{1}-\mathrm{O}_{2}$ atoms in ${ }^{1} \mathrm{O}_{4}\left(\mathrm{D}_{2 \mathrm{~h}}\right)$ with density of the wave function: $\rho\left(r_{b c p}\right)=0.0817$ au and the Laplacian of electronic density at critical point, $\nabla^{2} \rho\left(r_{b c p}\right)=0.3479 \mathrm{au}$. The results confirmed that van der Waals interaction between the $\mathrm{O}_{1}-\mathrm{O}_{2}$ atoms. Although, the AIM analysis reveals covalent bond formation between the $\mathrm{O}_{2}-\mathrm{O}_{4}$ with the Laplacian of electronic charge density of $\nabla^{2} \rho\left(r_{b c p}\right)=-0.7198$ au. As shown in Figure 3, furthermore, we are analyzed the structure of tetraoxygen on the triplet PES. AIM analyses of ${ }^{3} \mathrm{O}_{4}$ $\left(\mathrm{D}_{2 \mathrm{~h}}\right)$ confirm the presence of one BCP located between $\mathrm{O}_{1}-\mathrm{O}_{2}$ with $\rho\left(r_{b c p}\right)=0.0527 \mathrm{au}$, and $\nabla^{2} \rho\left(r_{b c p}\right)=0.2142 \mathrm{au}$. The results display the van der Waals interaction between $\mathrm{O}_{1}-\mathrm{O}_{2}$ atoms. In addition, another BCP is located between $\mathrm{O}_{2}-\mathrm{O}_{4}$ atoms in ${ }^{3} \mathrm{O}_{4}\left(\mathrm{D}_{2 \mathrm{~h}}\right)$ molecule with the electronic density $\rho\left(r_{b c p}\right)=0.5507 \mathrm{au}$, and the Laplacian of electronic density $\nabla^{2} \rho\left(r_{b c p}\right)=-0.7601 \mathrm{au}$. The AIM analysis shows the covalent bond formation between the $\mathrm{O}_{2}-\mathrm{O}_{4}$ atoms. So, this work suggestion is two van der Waals interaction and two covalent bonds in the structure of $\mathrm{O}_{4}\left(\mathrm{D}_{2 \mathrm{~h}}\right)$ molecule on the singlet and triplet states. The relative energies and Laplacian of electronic charge density analysis confirmed that the tetraoxygen molecule on the triplet state with
TABLE 3: The vibrational frequencies $\left(\mathrm{cm}^{-1}\right)$ of the reactants, products, and transition states calculated at the B3LYP level. The value in parentheses refers to experimental data [35].

\begin{tabular}{|c|c|}
\hline Species & Frequencies (B3LYP) \\
\hline${ }^{1} \mathrm{O}_{4}$ & $198,519,547,810,1432,1624$ \\
\hline${ }^{3} \mathrm{O}_{4}$ & $248,279,398,626,1471,1637$ \\
\hline IN1 & $246,332,414,521,567,759,776,984,1041$ \\
\hline IN2 & $156,184,370,546,554,666,791,842,1010$ \\
\hline IN3 & $73,254,411,602,652,775,921,930,1301$ \\
\hline IN4 & $17,47,52,57,121,521,1177,1371,1633$ \\
\hline TS1 & $-378,202,242,410,546,608,696,929,1042$ \\
\hline TS2 & $-163,93,174,251,369,696,759,921,1012$ \\
\hline TS3 & $-591,93,369,399,520,608,767,970,1052$ \\
\hline TS4 & $-152,265,355,420,576,795,874,992,1233$ \\
\hline TS5 & $-455,188,290,424,488,690,906,1250,1442$ \\
\hline TS6 & $-281,304,334,384,479,979,986,1110,1130$ \\
\hline OOSOO & $74,80,235,317,343,694,706,925,1005$ \\
\hline $\mathrm{SO}_{2}$ & 519 (518), 1178 (1151), 1377 (1362) \\
\hline $\mathrm{O}_{2}\left({ }^{1} \Delta_{\mathrm{g}}\right)$ & $1634(1484)$ \\
\hline $\mathrm{SO}_{4}\left(\mathrm{C}_{2 \mathrm{v}}\right)$ & $\begin{array}{l}310,478 \text { (490), } 485 \text { (498), 497, } 678 \text { (611), } 737 \text { (777), } 967 \\
(927), 1279 \text { (1267), } 1447 \text { (1437) }\end{array}$ \\
\hline $\mathrm{SO}_{4}\left(\mathrm{C}_{3 \mathrm{v}}\right)$ & $243,244,298,308,477,994,1035,1088,1089$ \\
\hline
\end{tabular}

$\mathrm{D}_{2 \mathrm{~h}}$ point group is more realable than the other suggested structures.

3.2. Initial Interactions of Reactants. Since the ground state of sulfur atom is triplet, the mechanism of $\mathrm{S}+\mathrm{O}_{4}$ reaction is considered on the triplet PES. In spite of numerous attempts, we could not find any transition state for the reaction on the triplet PES. Only two complexes between the reactants are found on the triplet PES. Therefore, our attempt focused on the singlet PES for finding some intermediate, transition state, products, and suggested mechanism for the reaction pathway at the B3LYP level. Therefore, in the first step, the sulfur atom in triplet state, ${ }^{3} \mathrm{~S}$, excited to the singlet state, and the reaction can continue in the singlet state This is explained as follows.

One stable reactant complex, IN1 $\left(\mathrm{O}_{2}-\mathrm{S}-\mathrm{O}_{2}\right)$, has been considered between the reactants on the singlet PES. The intermediate IN1 is formed when the sulfur atom bridged to the oxygen atoms of $\mathrm{O}_{4}$ using the formation of four van der Waals bonds and rupture two $\mathrm{O}_{2}-\mathrm{O}_{2}$ van der Waals interactions in $\mathrm{O}_{4}$ molecule. In the intermediate IN1, the newly formed S-O bonds are two types. One, bond lengths 
TABLE 4: Topological analyses of products in atomic units.

\begin{tabular}{lccccccc}
\hline & \multicolumn{2}{c}{$\mathrm{OOSOO}$} & $\mathrm{SO}_{2}$ & \multicolumn{2}{c}{$\mathrm{SO}_{4}\left(\mathrm{C}_{2 \mathrm{v}}\right)$} & $\mathrm{SO}\left(\mathrm{C}_{3 \mathrm{v}}\right)$ \\
& $\mathrm{O}-\mathrm{O}$ & $\mathrm{S}-\mathrm{O}$ & $\mathrm{S}-\mathrm{O}$ & $\mathrm{S}=\mathrm{O}$ & $\mathrm{S}-\mathrm{O}$ & $\mathrm{O}-\mathrm{O}$ & -0.6069 \\
$\lambda_{1}$ & -0.8486 & -0.4070 & -0.6145 & -0.6264 & -0.4161 & -0.3970 & -0.5801 \\
$\lambda_{2}$ & -0.8424 & -0.2703 & -0.5457 & -0.5500 & -0.3708 & -0.2838 & 1.6849 \\
$\lambda_{3}$ & 1.6457 & 0.5719 & 2.1282 & 2.0939 & 0.7131 & 0154 & 0.3015 \\
$\rho(r)$ & 0.3606 & 0.2283 & 0.3080 & 0.3283 & 0.2373 & 0.2038 & 0.3346 \\
$\nabla^{2} \rho(r)$ & -0.0453 & -0.1054 & 0.9680 & 0.9175 & -0.0738 & 0.4979 \\
$\varepsilon$ & 0.0073 & 0.5057 & 0.1261 & 0.1389 & 0.1222 & 0.3989 & 0.0462 \\
\hline
\end{tabular}

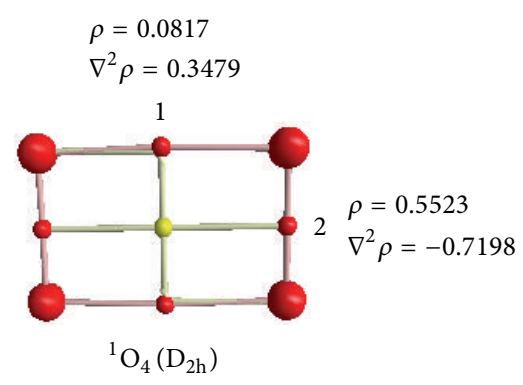

(a) $\rho=0.0527$

$\nabla^{2} \rho=0.2142$

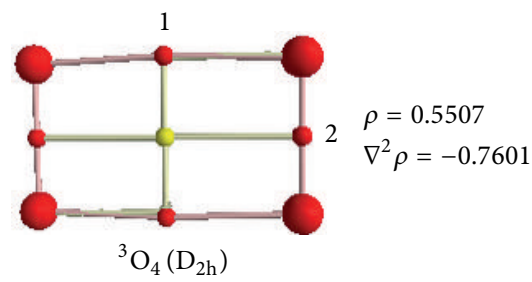

(b)

FIgURE 3: The values of the AIM theory topological parameters for bonds of tetraoxygen on the singlet and triplet PESs.

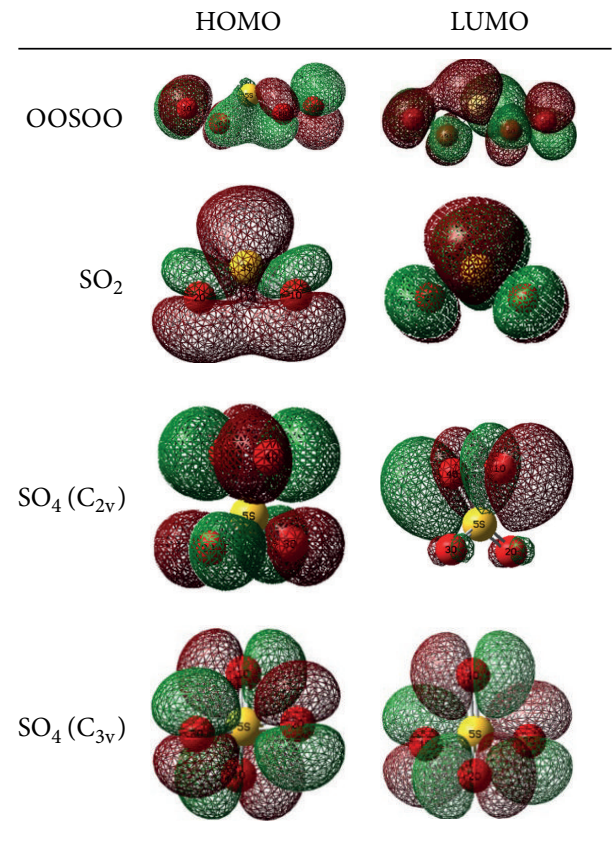

FIGURE 4: Frontier molecular orbitals of OOSOO, $\mathrm{SO}_{2}, \mathrm{SO}_{4}\left(\mathrm{C}_{2 \mathrm{v}}\right)$, and $\mathrm{SO}_{4}\left(\mathrm{C}_{3 \mathrm{v}}\right)$ molecules.

are $1.525 \AA$ and two they are $1.702 \AA$ at the B3LYP level with the formation relative energy of $-109.524 \mathrm{kcal} / \mathrm{mol}$. No transition states have been found for the formation of IN1 intermediate. Therefore, the results show that the formation of IN1 is a barrier-less and exothermic process. In the complex, four oxygen atoms of $\mathrm{O}_{4}$ are associated with sulfur atom and two three-membered rings are formed (see IN1 structure in Figure 1). In the first ring formation the lone pair of the $\mathrm{O}_{2}$ and $\mathrm{O}_{4}$ atoms of tetraoxygen interacts with the sulfur atom and in the second ring $\mathrm{O}_{1}$ and $\mathrm{O}_{3}$ atoms associate with the atomic sulfur. Molecular geometry indicates that the IN1 complex has $\mathrm{Cl}$ symmetry.

The stable reactant complex formation is confirmed by AIM topological analysis of wave function. Our analysis reveals the presence of bond critical points; one located between two oxygen atoms of $\mathrm{O}_{4}$ molecule and sulfur atom with density of wave function, $\left(\rho\left(r_{b c p}\right)=0.1698\right.$ au and $\left.\nabla^{2} \rho\left(r_{b c p}\right)=0.0245 \mathrm{au}\right)$ and the other located between two other oxygen and sulfur atoms $\left(\rho\left(r_{b c p}\right)=0.2267 \mathrm{au}\right.$ and $\left.\nabla^{2} \rho\left(r_{b c p}\right)=0.0196 \mathrm{au}\right)$. Therefore, all the O $\cdots \mathrm{S}$ interactions are of the van der Waals types. In addition, the topological analysis of the wave function shows the existence of two bond critical points; one is located between $\mathrm{O}_{1}$ and $\mathrm{O}_{3}\left(\rho\left(r_{b c p}\right)=0.2300 \mathrm{au}\right.$ and $\left.\nabla^{2} \rho\left(r_{b c p}\right)=0.2334 \mathrm{au}\right)$, and the other is located between $\mathrm{O}_{2}$ and $\mathrm{O}_{4}$ with the same electronic density and Laplacian. Calculated results allow us to classify the $\mathrm{O} \cdots \mathrm{O}$ interactions as being of the van der Waals type. The rings formation between $\mathrm{O}_{2} \mathrm{~S}_{5} \mathrm{O}_{4}$ and $\mathrm{O}_{1} \mathrm{~S}_{5} \mathrm{O}_{3}$ atoms also is lightened using AIM analysis. The topological analysis of the wave functions and their Laplacians are $\rho\left(r_{b c p}\right)=$ 0.1449 au and $\nabla^{2} \rho\left(r_{b c p}\right)=0.4256$ au, respectively.

3.3. Formation Pathways of $\mathrm{P} 1$ (OOSOO). There is one possible pathway for production of $\mathrm{P} 1$ as follows:

Path 1: $\mathrm{R} \rightarrow \mathrm{IN} 1 \rightarrow \mathrm{TS} 1 \rightarrow \mathrm{IN} 2 \rightarrow \mathrm{TS} 2 \rightarrow \mathrm{P} 1$ (OOSOO). 
TABLE 5: HOMO and LUMO energies (in atomic unit) of OOSOO, $\mathrm{SO}_{2}, \mathrm{SO}_{4}\left(\mathrm{C}_{2 \mathrm{v}}\right)$, and $\mathrm{SO}_{4}\left(\mathrm{C}_{3 \mathrm{v}}\right)$ molecules.

\begin{tabular}{lcccc}
\hline & OOSOO & $\mathrm{SO}_{2}$ & $\mathrm{SO}_{4}\left(\mathrm{C}_{2 \mathrm{v}}\right)$ & $\mathrm{SO}_{4}\left(\mathrm{C}_{3 \mathrm{v}}\right)$ \\
\hline$E_{\text {HOMO }}$ & -0.2763 & -0.3472 & -0.3640 & -0.3772 \\
$E_{\text {LUMO }}$ & -0.2153 & -0.1399 & -0.1613 & -0.3233 \\
$\Delta \varepsilon$ & -0.0610 & -0.2073 & -0.2027 & -0.0539 \\
\hline
\end{tabular}

TABLE 6: The thermodynamic data of the $\mathrm{S}+\mathrm{O}_{4}$ reaction on the singlet PES at the B3LYP method $(\mathrm{kcal} / \mathrm{mol})$.

\begin{tabular}{lcccc}
\hline Reaction & $\Delta E^{0}$ & $\Delta H^{0}$ & $\Delta G^{0}$ & $T \Delta S^{0}$ \\
\hline${ }^{1} \mathrm{~S}^{1} \mathrm{O}_{4} \rightarrow$ OOSOO & -67.694 & -68.286 & -62.177 & -6.108 \\
${ }^{1} \mathrm{~S}^{1} \mathrm{O}_{4} \rightarrow \mathrm{SO}_{2}+{ }^{1} \mathrm{O}_{2}\left({ }^{1} \Delta_{\mathrm{g}}\right)$ & -170.708 & -170.708 & -173.338 & 2.629 \\
${ }^{1} \mathrm{~S}^{1} \mathrm{O}_{4} \rightarrow \mathrm{SO}_{4}\left(\mathrm{C}_{2 \mathrm{v}}\right)$ & -187.450 & -188.042 & -179.147 & -8.896 \\
${ }^{1} \mathrm{~S}^{1} \mathrm{O}_{4} \rightarrow \mathrm{SO}_{4}\left(\mathrm{C}_{3 \mathrm{v}}\right)$ & -164.265 & -164.857 & -156.922 & -7.935 \\
\hline
\end{tabular}

As is shown in path 1 , the singlet reactants of $\mathrm{S}$ and $\mathrm{O}_{4}$ directly transformed to IN1 without entrancing any transition state. Then IN1 transformed to IN2 after passing TS1 with the energy barrier of $35.429 \mathrm{kcal} / \mathrm{mol}$ at the B3LYP level. In this step, one O-S van der Waals bond of three-membered ring structure in IN1 molecule ruptures and IN2 appears. IN2 is $86.279 \mathrm{kcal} / \mathrm{mol}$ lower than the ${ }^{1} \mathrm{~S}+{ }^{1} \mathrm{O}_{4}$ original reactant. TS1 has one imaginary frequency at $378 \mathrm{icm}^{-1}$ that is vibrated in the reaction coordinate. TS1 has a threemembered ring structure (see Figure 1). The electronic charge density and its Laplacian in ring critical points are 0.1712 and $0.4378 \mathrm{au}$, respectively. The intermediate IN2 converted into final product after passing TS2 with the energy barrier of $35.155 \mathrm{kcal} / \mathrm{mol}$ and imaginary frequency of $163 \mathrm{i} \mathrm{cm}^{-1}$ in the reaction coordinate. The $\mathrm{S}-\mathrm{O}$ bond of three-membered ring complex, IN2, is ruptured and converts to the final product $\mathrm{P} 1$. The conversion is an endothermic process but the overall reaction from singlet reactants is exothermic with the reaction enthalpy $-68.286 \mathrm{kcal} / \mathrm{mol}$ and is spontaneous with the Gibbs free energy $-62.177 \mathrm{kcal} / \mathrm{mol}$. All steps of reaction as formation of ring structure and its collapse are confirmed by electronic charge density analysis using AIM calculation results. Formation channel of product P1 with two transition states and lower level of energy barriers is favorable process from kinetic point of view.

3.4. Formation Pathways of $\mathrm{P} 2\left(\mathrm{O}_{2}\left({ }^{1} \Delta_{g}\right)+\mathrm{SO}_{2}\right)$. There is one possible pathway for production of $\mathrm{P} 2$ as follows:

Path $2: \mathrm{R} \rightarrow \mathrm{IN} 1 \rightarrow \mathrm{TS} 1 \rightarrow \mathrm{IN} 2 \rightarrow \mathrm{TS} 3 \rightarrow \mathrm{IN} 3 \rightarrow$ $\mathrm{TS} 4 \rightarrow \mathrm{IN} 4 \rightarrow \mathrm{P} 2\left({ }^{1} \mathrm{O}_{2}\left({ }^{1} \Delta_{\mathrm{g}}\right)+\mathrm{SO}_{2}\right)$.

As shown in Figure 2, formation of the intermediate IN2 is similar to path $\mathrm{P} 1$; then, it transforms into IN3 using TS3 with energy barrier of $11.048 \mathrm{kcal} / \mathrm{mol}$ and imaginary frequency of $591 \mathrm{i} \mathrm{cm}^{-1}$. The $\mathrm{O}_{2}-\mathrm{O}_{4}$ bond in ring structure of TS3 is $51 \%$ longer in comparison with the corresponding bond in IN2. Four-membered ring complex, IN3, (see Figure 1) undergoes elongation of $\mathrm{O}_{3}-\mathrm{S}$ bond and collapse of fourmembered ring structure turn to IN4 after entrancing TS4 with the energy barrier of $11.892 \mathrm{kcal} / \mathrm{mol}$ and imaginary frequency of $152 \mathrm{icm}^{-1}$. The elongation of the $\mathrm{O}_{3}-\mathrm{S}$ bond of TS4 almost 0.379 corresponds to a relative increase of $22 \%$ in TS4 compared to the IN3 molecule. Obtained specie is known as a complex between singlet molecular oxygen and sulfur dioxide. Then the product complex IN4 can directly transform into the product ${ }^{1} \mathrm{O}_{2}+\mathrm{SO}_{2}$ through $\mathrm{O}-\mathrm{O}$ bond rupture without any transition state. Singlet molecular oxygen due to spin multiplicity changes and transforms to triplet oxygen through a relaxation process. The reaction thermodynamic parameters indicate that $\mathrm{P} 2$ complex, ${ }^{1} \mathrm{O}_{2}\left({ }^{1} \Delta_{\mathrm{g}}\right)+\mathrm{SO}_{2}$, formation is exothermic with enthalpy of reaction, $-170.708 \mathrm{kcal} / \mathrm{mol}$, in comparison with the original reactants. In all steps of path $\mathrm{P} 2$, the formation of products from reactants is confirmed using related IRC curves.

3.5. Formation Pathways of $\mathrm{P} 3\left(\mathrm{SO}_{4}\left(\mathrm{C}_{2 v}\right)\right)$. For production of $\mathrm{P} 3$, there is one possible pathway as follows:

$$
\begin{aligned}
& \text { Path } 3: \mathrm{R} \rightarrow \mathrm{IN} 1 \rightarrow \mathrm{TS} 1 \rightarrow \mathrm{IN} 2 \rightarrow \mathrm{TS} 3 \rightarrow \mathrm{IN} 3 \rightarrow \\
& \mathrm{TS} 4 \rightarrow \mathrm{IN} 4 \rightarrow \mathrm{TS} 5 \rightarrow \mathrm{P} 3 .
\end{aligned}
$$

In this path, the formation of the intermediate IN4 is similar to path P2. Then, the IN4 exchange to final product through TS5 by formation of $\mathrm{S}-\mathrm{O}_{4}$ and $\mathrm{O}_{3}-\mathrm{S}$ bonds. For this step, barrier height is $33.603 \mathrm{kcal} / \mathrm{mol}$. The optimized structure of transition state TS5 shows that $\mathrm{O}_{3}-\mathrm{S}$ bond length is $45 \%$ longer than corresponding bond in $\mathrm{SO}_{4}$. On the other hand, newly formed bond, $\mathrm{O}_{4}-\mathrm{S}$, is $51 \%$ greater than the corresponding bond in IN4 molecule. Imaginary frequency of TS5 is $455 \mathrm{i} \mathrm{cm}^{-1}$.

The reaction thermodynamic parameters indicate that P3 formation process is exothermic by $188.042 \mathrm{kcal} / \mathrm{mol}$ releasing heat and spontaneous with $-179.147 \mathrm{kcal} / \mathrm{mol}$ in Gibbs free energy at atmospheric pressure and $298.15 \mathrm{~K}$ temperature. The formation of products along the path is confirmed using AIM results and IRC curve.

3.6. Formation Pathways of $\mathrm{P} 4\left(\mathrm{SO}_{4}\left(C_{3 v}\right)\right)$. For production of $\mathrm{P} 4$, there is one possible pathway as follows:

$$
\begin{aligned}
& \text { Path } 4: \mathrm{R} \rightarrow \mathrm{IN} 1 \rightarrow \mathrm{TS} 1 \rightarrow \mathrm{IN} 2 \rightarrow \mathrm{TS} 3 \rightarrow \mathrm{IN} 3 \rightarrow \\
& \mathrm{TS} 4 \rightarrow \mathrm{IN} 4 \rightarrow \mathrm{TS} 5 \rightarrow \mathrm{P} 3 \rightarrow \mathrm{TS} 6 \rightarrow \mathrm{P} 4 .
\end{aligned}
$$

In this path, the formation of the P3 is similar to path $\mathrm{P} 3$. Then $\mathrm{P} 3$ can be converted into the $\mathrm{P} 4$ by angle-variation through TS6 transition state. The angle of $\mathrm{O}_{3} \mathrm{SO}_{4}$ in $\mathrm{P} 3$ is $59.6^{\circ}$ while it is $106.0^{\circ}$ in $\mathrm{P} 4$. The breaking bond of $\mathrm{O}_{3}-\mathrm{O}_{4}$ is 1.576 in P3 that extend to 2.176 in TS6. The energy height of this process is $18.231 \mathrm{kcal} / \mathrm{mol}$ and imaginary frequency of TS6 is $281 \mathrm{~cm}^{-1}$.

The reaction thermodynamic parameters show that $\mathrm{P} 4$ formation process is exothermic by $164.857 \mathrm{kcal} / \mathrm{mol}$ releasing heat and spontaneous with $-156.922 \mathrm{kcal} / \mathrm{mol}$ in Gibbs free energy. The $\mathrm{SO}_{4}\left(\mathrm{C}_{2 \mathrm{v}}\right)$ molecule has been confirmed in both the experimental and theoretical studies, while $\mathrm{SO}_{4}\left(\mathrm{C}_{3 \mathrm{v}}\right)$ molecule has been only confirmed in the theoretical studies. In this work, we are obtained both of them that molecule with $\mathrm{C}_{2 \mathrm{v}}$ symmetry is more stable than another. In summary, the ${ }^{1} \mathrm{~S}+{ }^{1} \mathrm{O}_{4}$ reaction is energetically feasible 
to formation of all four products all over corresponding paths which all step of reaction confirm using IRC and AIM calculations.

3.7. Topological Analysis of Electronic Density of the Products. AIM topological analysis has been shown to provide important information about many different chemical systems by an analysis of molecular electron density distribution. The electron density, $\rho(r)$, density Laplacian, $\nabla^{2} \rho(r)$, and bond ellipticity, $\varepsilon=\left(\lambda_{1} / \lambda_{2}\right)-1$, at bond critical points (BCP) have been extracted using AIM topological analysis. The $\lambda_{1}, \lambda_{2}$, and $\lambda_{3}$ are the eigenvalues of the Hessian matrix. The first two eigenvalues correspond to the perpendicular curvatures and the latter provides curvatures along the internuclear axis. According to the AIM topological analysis, electron density, $\rho(r)$, and Laplacian of the electron density, $\nabla^{2} \rho(r)$, are used to describe the strength and the characteristic of the bond, respectively. According to the theory of AIM, the positive value of the Laplacian $\left(\nabla^{2} \rho(r)\right)$ indicates a weak interaction or an ionic bond; however, the negative value of the Laplacian shows a strong covalent bond between the atoms. The ellipticity shows that the ratio of the rate of density decrease in two directions perpendicular to the bond path at the bond critical point.

The topological analysis of the electronic density were performed for all bonds in the OOSOO, $\mathrm{SO}_{2}$ and $\mathrm{SO}_{4}\left(\mathrm{C}_{2 \mathrm{v}}\right)$, and $\mathrm{SO}_{4}\left(\mathrm{C}_{3 \mathrm{v}}\right)$ species as stable products of our studied reaction. The topological characteristics in the BCP's of S$\mathrm{O}$ and $\mathrm{O}-\mathrm{O}$ bonds are tabulated in Table 4. In addition, the $\nabla^{2} \rho(r)$ values in Table 4 indicate that the every bond in OOSOO has covalent character $\left(\nabla^{2} \rho(r)<0\right)$. Their electron density values show that the bond strength manner $\mathrm{O}-\mathrm{O}>\mathrm{S}-$ $\mathrm{O}$ is corresponding to the electronic charge densities 0.3606 and $0.2283 \mathrm{au}$, respectively.

In $\mathrm{SO}_{4}\left(\mathrm{C}_{2 \mathrm{v}}\right)$ molecule, the $\mathrm{S}-\mathrm{O}$ bond has covalent character with Laplacian of $-0.0738 \mathrm{au}$, whereas the $\mathrm{S}=\mathrm{O}$ bond has electrostatic interaction nature with Laplacian of the electron density value 0.9675 and $\mathrm{O}-\mathrm{O}$ bond with $0.3346 \mathrm{au}$ in $\nabla^{2} \rho(r)$ has van der Waals origin. The $\mathrm{S}=\mathrm{O}$ bond in $\mathrm{SO}_{4}$ $\left(\mathrm{C}_{2 \mathrm{v}}\right)$, in comparison with corresponding bonds in $\mathrm{SO}_{2}$ and $\mathrm{SO}_{4}\left(\mathrm{C}_{3 \mathrm{v}}\right)$ molecules, has high electronic density. The results have confirmed that mentioned bond in $\mathrm{SO}_{4}\left(\mathrm{C}_{2 \mathrm{v}}\right)$ is stronger than the corresponding bonds in other species. The Laplacian of $\mathrm{S}=\mathrm{O}$ bond in $\mathrm{SO}_{2}$ and $\mathrm{SO}_{4}\left(\mathrm{C}_{2 \mathrm{v}}\right)$ is very similar and its absolute value is greater than Laplacian of corresponding bond in $\mathrm{SO}_{4}\left(\mathrm{C}_{3 \mathrm{v}}\right)$. The results suggested that $\mathrm{S}=\mathrm{O}$ bonds in three mentioned molecules have electrostatic nature and can be ionic origin.

The values for the ellipticity of various bonds for three products are listed in Table 4 . The high ellipticity $(\varepsilon)$ for $\mathrm{S}-\mathrm{O}$ bond in OOSOO molecule shows nonsymmetrical distribution of density about the bond path, whereas low value belongs to the $\mathrm{O}-\mathrm{O}$ bond which is corresponding with symmetrical distribution of density between two atoms. In $\mathrm{SO}_{4}\left(\mathrm{C}_{3 \mathrm{v}}\right)$ molecule, all of the bonds have the same ellipticity $(0.0462 \mathrm{au})$. This manner shows that bonds have the same symmetry in distribution of $\pi$ bonding character. Comparison of the $\mathrm{S}-\mathrm{O}$ bond ellipticities in all of species shows that the S-O electron density in OOSOO builds up in a particular orientation and it reveals nonsymmetrical distribution of density between two atoms.

3.8. Molecular Orbital Analyses of the Products. The features of the HOMO and LUMO for products are calculated by B3LYP/6-311+G (3df) level in gaseous phase. The HOMO energy characterizes the ability of electron to donate, and the LUMO energy characterizes the ability of electron to accept [36]. The energy gap between HOMO and LUMO characterizes whether the molecules are chemically stable or not. The energy band gap $(\Delta \varepsilon)$ (transition from HOMO to LUMO), ionization potential, and electron affinity of the OOSOO, $\mathrm{SO}_{2}, \mathrm{SO}_{4}\left(\mathrm{C}_{2 \mathrm{v}}\right)$, and $\mathrm{SO}_{4}\left(\mathrm{C}_{3 \mathrm{v}}\right)$ species can be seen in Table 5. The HOMO-LUMO energy gap results predict that the $\mathrm{SO}_{2}(0.2073 \mathrm{au})$ and $\mathrm{SO}_{4}\left(\mathrm{C}_{2 \mathrm{v}}\right)(0.2027 \mathrm{au})$ with large energy gaps $(\Delta \varepsilon)$ are more stable than the OOSOO $(0.0 .610 \mathrm{au})$ and $\mathrm{SO}_{4}\left(\mathrm{C}_{3 \mathrm{v}}\right)(0.0539 \mathrm{au})$ molecules. The frontier molecular orbitals of four products are depicted in Figure 4. In OOSOO molecule, the LUMO is localized on the bond between oxygen-sulfur atoms. The HOMO is mainly composed on the p-type atomic orbitals of oxygen and sulfur atoms. In $\mathrm{SO}_{2}$ molecule, the $\mathrm{HOMO}$ orbital is localized on the bond between oxygen-sulfur atoms while the LUMO is composed in the $\pi$ type orbitals of tree atoms. In addition, results show that HOMO orbital is localized on the $\pi$ type orbitals of oxygen atoms in $\mathrm{SO}_{4}\left(\mathrm{C}_{2 \mathrm{v}}\right)$ while the LUMO is composed mainly just in the $\pi$ type orbitals of two oxygen atoms. Finally, in $\mathrm{SO}_{4}\left(\mathrm{C}_{3 \mathrm{v}}\right)$, the HOMO and LUMO orbitals that are completely similar are localized in the p-type atomic orbitals of oxygen atoms.

\section{Conclusion}

In the percent work, the reaction mechanism of sulfur atom with $\mathrm{O}_{4}$ molecule is investigated on the singlet PES. The experimental and theoretical studies show that $\mathrm{O}_{4}$ has different structures with various points group. In the neutral structure of tetraoxygen with $\mathrm{D}_{2 \mathrm{~h}}$ point group and triplet state are more stable than singlet state and other structures. In spite of numerous attempts, no transition state has been found for the $\mathrm{S}_{+} \mathrm{O}_{4}$ reaction on the triplet PES. Therefore, the details of theoretical investigation on the singlet PES of $\mathrm{S}+\mathrm{O}_{4}$ reaction have been carried out at the $\mathrm{B} 3 \mathrm{LYP} / 6-311+\mathrm{G}$ (3df) and CCSD levels. Therefore, in the first step, the sulfur atom on the triplet state, ${ }^{3} \mathrm{~S}+{ }^{1} \mathrm{O}_{4}$, is excited to the singlet state, ${ }^{1} \mathrm{~S}_{+}{ }^{1} \mathrm{O}_{4}$, and the reaction continues in the singlet state. One stable reactant complex, IN1 $\left(\mathrm{O}_{2}-\mathrm{S}-\mathrm{O}_{2}\right)$, has been considered between the reactants on the singlet PES. Through variety of $\mathrm{IN} 1$ transformations, four kinds of products OOSOO, $\mathrm{SO}_{2}+$ $\mathrm{O}_{2}\left({ }^{1} \Delta_{\mathrm{g}}\right), \mathrm{SO}_{4}\left(\mathrm{C}_{2 \mathrm{v}}\right)$, and $\mathrm{SO}_{4}\left(\mathrm{C}_{3 \mathrm{v}}\right)$ are obtained which have enough thermodynamic stability. In conclusion, $\mathrm{SO}_{4}\left(\mathrm{C}_{2 \mathrm{v}}\right)$ is the most stable product and its production is spontaneous and exothermic reaction with -188.042 and $-179.147 \mathrm{kcal} / \mathrm{mol}$ in Gibbs free energy and enthalpy of reaction at the B3LYP level, respectively. In kinetic viewpoint, it is expected that the formation channel of P1 with two transition states and low level energy barriers is favorable process. 


\section{Conflict of Interests}

The authors declare that there is no conflict of interests regarding the publication of this paper.

\section{References}

[1] G. N. Lewis, "The magnetism of oxygen and the molecule $\mathrm{O}_{4}$," Journal of the American Chemical Society, vol. 46, no. 9, pp. 2027-2032, 1924.

[2] A. J. C. Varandas and J. L. Llanio-Trujillo, "On triplet tetraoxygen: ab initio study along minimum energy path and global modelling," Chemical Physics Letters, vol. 356, no. 5-6, pp. 585$594,2002$.

[3] O. Prasad, L. Sinha, N. Misra et al., "Study of electrostatic potential surface and molecular orbitals of $\mathrm{O}_{4}$ nano cluster by first principles," Scholars Research Library, vol. 1, no. 2, pp. 7985, 2009.

[4] C. A. Long and G. E. Ewing, "Spectroscopic investigation of van der waals molecules. I. The infrared and visible spectra of $\left(\mathrm{O}_{2}\right)_{2}$," The Journal of Chemical Physics, vol. 58, pp. 4824-4834, 1973.

[5] D. S. Peterka, "Unraveling the mysteries of metastable $\mathrm{O}_{4}$ ", Journal of Chemical Physics, vol. 110, no. 13, pp. 6095-6098, 1999.

[6] K. M. Dunn, G. E. Scuseria, and H. F. Schaefer III, “The infrared spectrum of cyclotetraoxygen, $\mathrm{O}_{4}$ : a theoretical investigation employing the single and double excitation coupled cluster method," The Journal of Chemical Physics, vol. 92, no. 10, pp. 6077-6080, 1990.

[7] R. Hernández-Lamoneda and A. Ramírez-Solís, "Reactivity and electronic states of $\mathrm{O}_{4}$ along minimum energy paths," Journal of Chemical Physics, vol. 113, no. 10, pp. 4139-4145, 2000.

[8] D. Pillay, Y. Wang, and G. S. Hwang, "Prediction of tetraoxygen formation on rutile $\mathrm{TiO}_{2}(110)$," Journal of the American Chemical Society, vol. 128, no. 43, pp. 14000-14001, 2006.

[9] E. T. Seidl and H. F. Schaefer III, "Is there a transition state for the unimolecular dissociation of cyclotetraoxygen $\left(\mathrm{O}_{4}\right)$ ?" The Journal of Chemical Physics, vol. 96, no. 2, pp. 1176-1182, 1992.

[10] V. Aquilanti, D. Ascenzi, M. Bartolomei et al., "Molecular beam scattering of aligned oxygen molecules. The nature of the bond in the $\mathrm{O}_{2}-\mathrm{O}_{2}$ dimer," Journal of the American Chemical Society, vol. 121, no. 46, pp. 10794-10802, 1999.

[11] S. J. Arnold, E. A. Ogryzlo, and H. Witzke, "Some new emission bands of molecular oxygen," The Journal of Chemical Physics, vol. 40, no. 6, pp. 1769-1770, 1964.

[12] H. Helm and C. W. Walter, "Observation of electronically excited states of tetraoxygen," The Journal of Chemical Physics, vol. 98, no. 7, pp. 5444-5449, 1993.

[13] F. Cacace, G. de Petris, and A. Troiani, "Experimental detection of tetraoxygen," Angewandte Chemie International Edition, vol. 40, pp. 4062-4065, 2001.

[14] H. M. Bevsek, M. Ahmed, D. S. Peterka, F. C. Sailes, and A. G. Suits, "Direct detection and spectroscopy of $\mathrm{O}_{4}$," Faraday Discussions, vol. 108, pp. 131-138, 1997.

[15] V. Adamantides, D. Neisius, and G. Verhaegen, "Ab initio study of the $\mathrm{O}_{4}$ molecule," Chemical Physics, vol. 48, no. 2, pp. 215-220, 1980.

[16] I. Røeggen and E. W. Nilssen, "Prediction of a metastable $\mathrm{D}_{3 h}$ form of tetra oxygen," Chemical Physics Letters, vol. 157, no. 5, pp. 409-414, 1989.

[17] F. A. Gorelli, L. Ulivi, M. Santoro, and R. Bini, “The $\varepsilon$ phase of solid oxygen: evidence of an $\mathrm{O}_{4}$ molecule lattice," Physical Review Letters, vol. 83, no. 20, pp. 4093-4096, 1999.
[18] L. F. Lundegaard, G. Weck, M. I. McMahon, S. Desgreniers, and P. Loubeyre, "Observation of an $\mathrm{O}_{8}$ molecular lattice in the $\varepsilon$ phase of solid oxygen," Nature, vol. 443, no. 7108, pp. 201-204, 2006.

[19] M. Hotokka and P. Pyykkö, "An ab initio study of bonding trends in the series $\mathrm{BO}_{3}^{3-}, \mathrm{CO}_{3}^{2-}, \mathrm{NO}_{3}^{-}$and $\mathrm{O}_{4}\left(\mathrm{D}_{3 h}\right)$," Chemical Physics Letters, vol. 157, no. 5, pp. 415-418, 1989.

[20] A. H. Jubert and E. L. Varetti, "On the possible existence of the $\mathrm{O}_{4}$ molecule with $\mathrm{D}_{3 h}$ symmetry," Anales de Química, vol. 82, pp. 227-230, 1986 (Spanish).

[21] H. R. Pruppacher and J. D. Klett, Microphysics of Clouds and Precipitation, Reidel, Boston, Mass, USA, 1980.

[22] M. W. Wong, Y. Steudel, and R. Steudel, "Structures and vibrational spectra of the sulfur-rich oxides $\mathrm{S}_{n} \mathrm{O}(n=4-9)$ : the importance of $\pi^{*}-\pi^{*}$ interactions," Chemistry $A$, vol. 13, no. 2, pp. 502-514, 2007.

[23] A. Jacob and C. A. Winkler, "Kinetics of the reactions of oxygen atoms and nitrogen atoms with sulphur trioxide," Journal of the Chemical Society, Faraday Transactions, vol. 68, pp. 2077-2082, 1972.

[24] M. L. McKee, "Computational studies on $\mathrm{SO}_{4}$ and $\mathrm{S}_{2} \mathrm{O}_{3}$," Journal of the American Chemical Society, vol. 115, no. 20, pp. 9136-9142, 1993.

[25] L. Schriver, D. Carrere, A. Schriver, and K. Jaeger, "Matrixisolation photolysis of $\mathrm{SO}_{2}, \mathrm{O}_{3}$ and $\mathrm{H}_{2} \mathrm{O}$ : evidence for the $\mathrm{H}_{2} \mathrm{O}: \mathrm{SO}_{3}$ complex," Chemical Physics Letters, vol. 181, no. 6, pp. 505-511, 1991.

[26] R. Kugel and H. Taube, "Infrared spectrum and structure of matrix-isolated sulfur tetroxide," Journal of Physical Chemistry, vol. 79, no. 20, pp. 2130-2135, 1975.

[27] L. S. Levitt, "A new mechanism for persulphate oxidations," Canadian Journal of Chemistry, vol. 31, no. 10, pp. 915-922, 1953.

[28] M. J. Frisch, G. W. Trucks, H. B. Schlegel et al., Pople JA Gaussian 03, Revision B.03, Gaussian, Pittsburgh, Pa, USA, 2003.

[29] A. D. Becke, "A new mixing of hartree-fock and local densityfunctional theories," The Journal of Chemical Physics, vol. 98, no. 2, pp. 1372-1377, 1993.

[30] G. E. Scuseria and H. F. Schaefer III, "Is Coupled Cluster Singles and Doubles (CCSD) more computationally intensive than Quadratic Configuration Interaction (QCISD)?” The Journal of Chemical Physics, vol. 90, no. 7, pp. 3700-3703, 1989.

[31] G. E. Scuseria, C. L. Janssen, and H. F. Schaefer III, "An efficient reformulation of the closed-shell Coupled Cluster Single and Double Excitation (CCSD) equations," The Journal of Chemical Physics, vol. 89, no. 12, pp. 7382-7387, 1988.

[32] C. Gonzalez and H. B. Schlegel, "Reaction path following in mass-weighted internal coordinates," Journal of Physical Chemistry, vol. 94, no. 14, pp. 5523-5527, 1990.

[33] R. G. Parr and W. Yang, Density-Functional Theory of Atoms and Molecules, Oxford University Press, Oxford, UK, 1989.

[34] F. Biegler-Konig and J. Schoenbohm, AIM2000, Buro fur Innovative Software, Bielefeld, Germany, 2nd edition, 2002.

[35] R. D. Johnson III and NIST, Eds., "Computational chemistry comparison and benchmark database," NIST Standard Reference Database, Number 69, April, 2013, http://cccbdb.nist.gov/.

[36] P. W. Atkins, Physical Chemistry, Oxford University Press, Oxford, UK, 2001. 

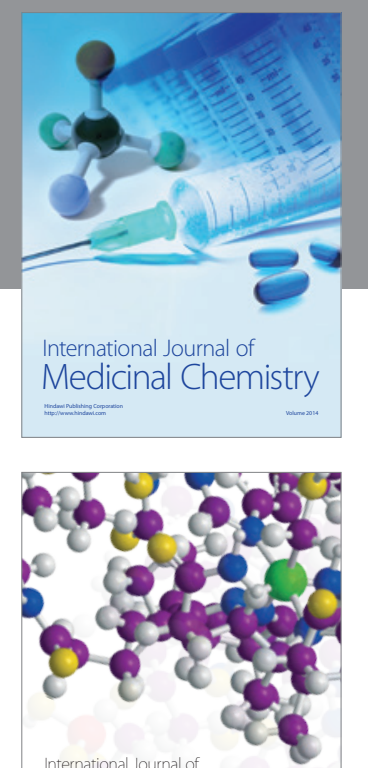

\section{Carbohydrate} Chemistry

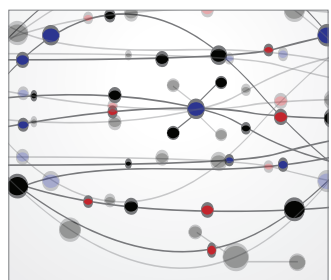

The Scientific World Journal
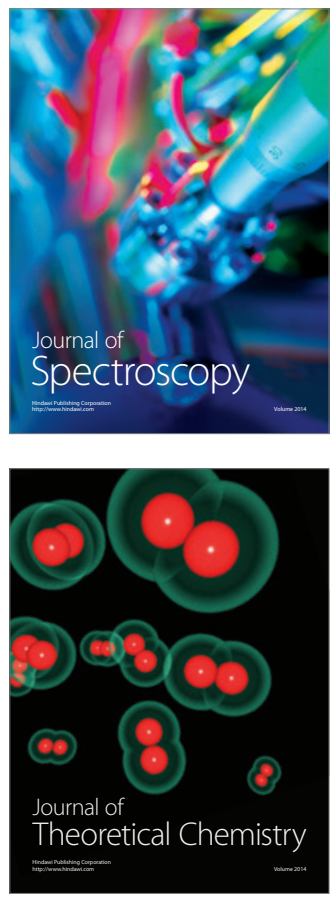
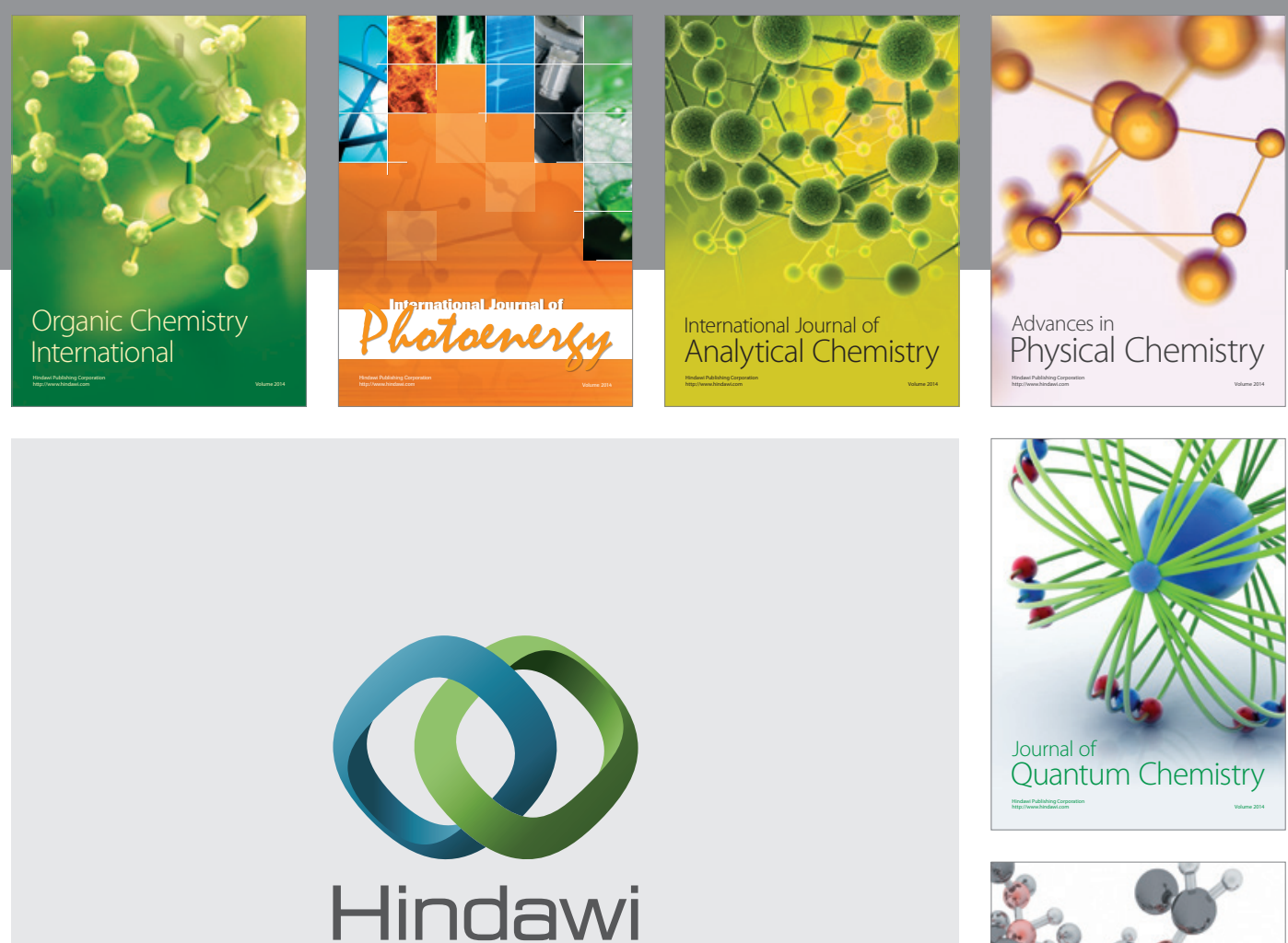

Submit your manuscripts at

http://www.hindawi.com

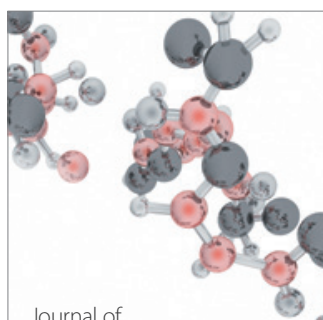

Analytical Methods

in Chemistry

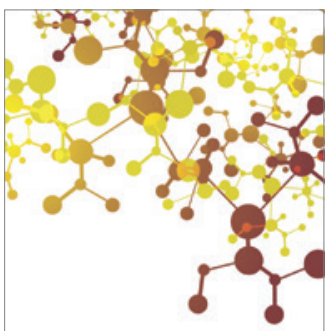

Journal of

Applied Chemistry

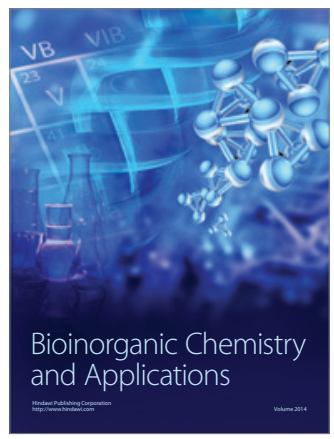

Inorganic Chemistry
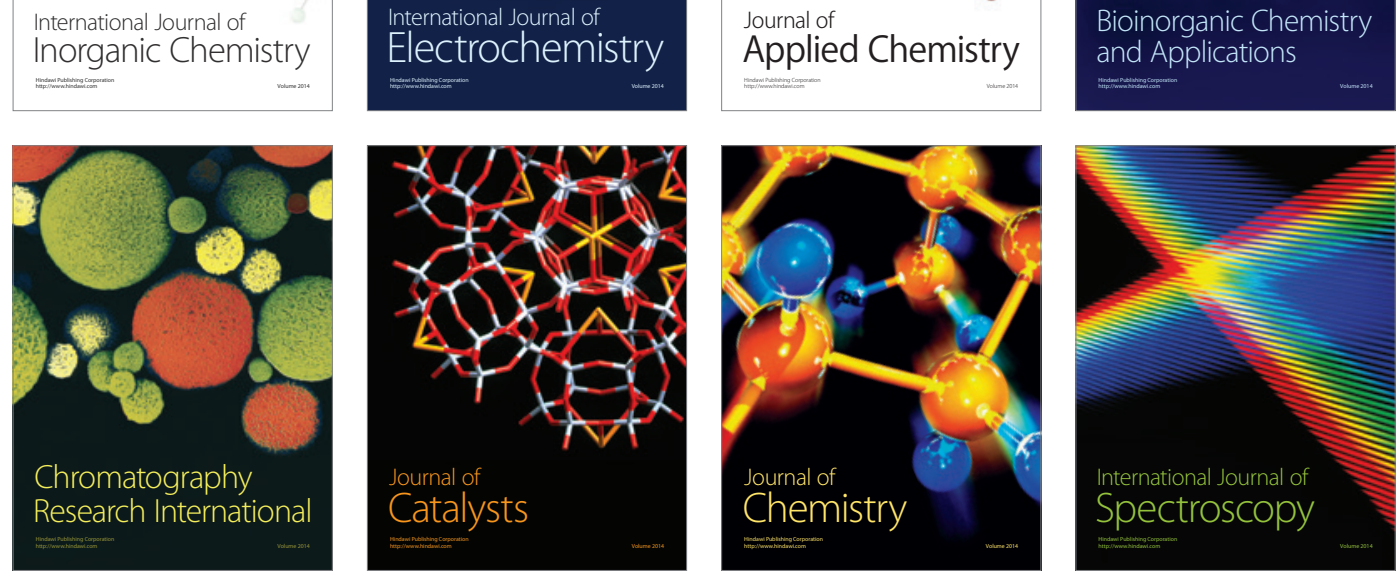